\title{
The Engineering behavior and the Properties of Phosphorit and Gypsum on the Resistance strength of Concrete
}

\author{
Hesham Alsharie
}

\begin{abstract}
Phosphorite buildup from Phosphorites that negatively affect nature. The reuse of this waste is carried out in this study by replacing percentage of cement by Phosphorite $(P)$ residue and gypsum (G). The cement of the Phosphorites and gypsum was replaced by the following percentages of weight: for masonry $(0 \%$, $5 \%, 10 \% 15 \%, 25 \%$, and $50 \%)$, for concrete $(0 \%, 10 \%, 25 \%, 35 \%$, and 50\%), number of samples (36 masonry samples, 30 cube samples, 20 cylinder samples, total 86 samples) Standard Resistance strength tests were carried out at (Asia lab - Irbid) to verify the strength of pressure in new mixtures. The results showed that replacing of cement by $P$ residues and $G$ increased the strength of masonry sample (MGPC-25\%) by (42\%). The results showed that replacing of cement by Phosphorite residues and gypsum increased the strength of concrete cubes sample (CGPC-25\%) by (13\%). The results showed that replacing of cement by Phosphorite residues and gypsum increased the strength of concrete cylinders sample (CYGPC-25\%) by (20\%). It is proposed to use Phosphorite residues and gypsum as an alternative to the cement by limited percentage, because increasing the gypsum percentage causing failures and weakness of concrete.
\end{abstract}

Keywords - Resistance strength, natural impact, cost, gypsum (G), Phosphorite.

\section{NTRODUCTION}

The Gypsum deposits of Jordan were first recorded in 1970, since that point several exploration and Geologic Studies are administrated to estimate the reserves and properties of those deposits. Gypsum is teeming material accessible within the earth, that is a lot of a mineral that's scattered in nature with one in every of its gilded forms or matter rocks. Its presence on the surface of the world or at depths up to 350m Gypsum is salt mineral composed of calcium sulphate dehydrate, with the statement $\mathrm{CaSO} 4 \cdot 2 \mathrm{H} 2 \mathrm{O}[1,2,3,4,5]$.

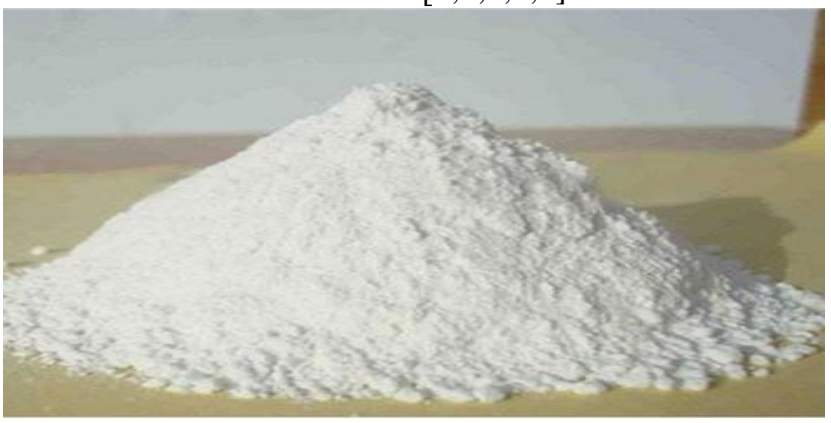

Figure 1: Gypsum $\left(\mathrm{CaSO}_{4} \cdot{ }_{2} \mathrm{H}_{2} \mathrm{O}\right)$

Revised Manuscript Received on February 05, 2020

* Correspondence Author

Dr.Hesham Alsharie*, Department of civil Engineering, College of Engineering, jerash University Email: h.alsharea@jpu.edu.jo

(c) The Authors. Published by Blue Eyes Intelligence Engineering and Sciences Publication (BEIESP). This is an open access article under the CC BY-NC-ND license (http://creativecommons.org/licenses/by-nc-nd/4.0/)
The results showed that replacing of cement by Phosphorite residues and gypsum increased the strength of masonry sample (MGPC-25\%) by (42\%). The results showed that replacing of cement by Phosphorite residues and gypsum increased the strength of concrete cubes sample (CGPC-25\%) by (13\%). The results showed that replacing of cement by Phosphorite residues and gypsum increased the strength of concrete cylinders sample (CYGPC-25\%) by (20\%). It is proposed to use Phosphorite residues and gypsum as an alternative to the cement by limited percentage, because increasing the gypsum percentage causing failures and weakness of concrete $[6,7$,

\section{LITERATURE REVIEW}

In this study, several experimental models were used including: $(0.5 * 0.5 * 0.5 \mathrm{~cm})$ masonry samples, $(15 * 15 *$ $15 \mathrm{~cm})$ of concrete cubes, and finally $(15 * 30 \mathrm{~cm})$ concrete cylinders. Regarding the experimental tests, cubes were left in set for 7 , and 28 days. The results show that the use of Phosphorite wastes replaced cement increased the Resistance strength of masonry by $27.2 \%$. In concrete cubes, the utilization of Phosphorite wastes replaced cement increased Resistance strength by $25.4 \%$. In concrete cylinders, utilization of Phosphorite wastes replaced cement increased the Resistance strength by $30.1 \%$. Subsequently [8, 9].

Other study conducted a similar experiment including: $(0.5 *$ $0.5 * 0.5 \mathrm{~cm})$ masonry samples, $(15 * 15 * 15 \mathrm{~cm})$ of concrete cubes, and $(15 * 30 \mathrm{~cm})$ concrete cylinders. The experimental samples were then cured by a 7 and 28 days of incubation for different test groups. The results indicated that the use of Phosphorite wastes increased the Resistance strength of masonry by $29 \%$. The resistance strength has increased by $26 \%$ and $34 \%$ for experimental cubes and cylinders respectively after the use of Phosphorite wastes as previously described [3].

\section{DESTINATIONS OF THE RESEARCH}

This research aims to investigate the possibility of victimization the Phosphorite wastes within the production of masonry and concrete, to extend the Resistance strength of masonry and concrete once adding specific proportions of Phosphorite wastes at intervals the quality specifications. 
The Engineering behavior and the Properties of Phosphorit and Gypsum on the Resistance strength of

\section{Concrete}

\section{METHODOLOGY}

So as to actuate the adequate measure of Phosphorite wastes mixture that has associate degree improvement in the masonry group [4], and concrete properties, the masonry samples were divided into five classifications according to the ratio of Phosphorite wastes and Gypsum to cement. Each category, six cube specimens were prepared and tested [10]. The classifications are:

Six cube specimens with null Phosphorite wastes and Gypsum (MP).

Six cube specimens with 5\%Phosphorite wastes and 5\%Gypsum (MGPC5\%).

Six cube specimens with $10 \%$ Phosphorite wastes and 10\%Gypsum (MGPC10\%).

Six cube specimens with $15 \%$ Phosphorite wastes and 15\%Gypsum (MGPC15\%).

Six cube specimens with 25\%Phosphorite wastes and 25\%Gypsum (MGPC25\%).

Six cube specimens with 50\%Phosphorite wastes and 50\%Gypsum (MGPC50\%).

While concrete, the samples were divided into five classifications according to the ratio of Phosphorite wastes

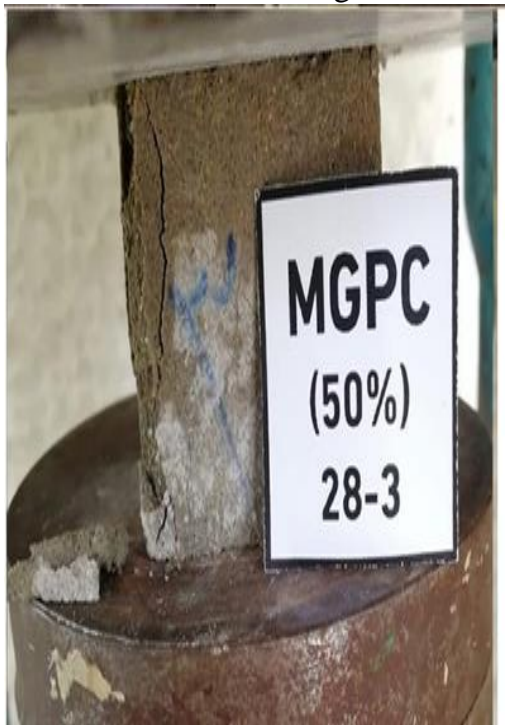

(a)

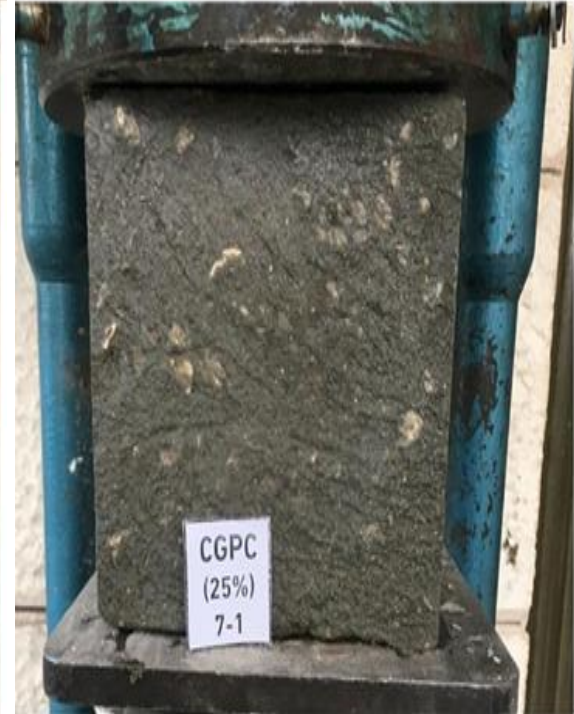

(b)

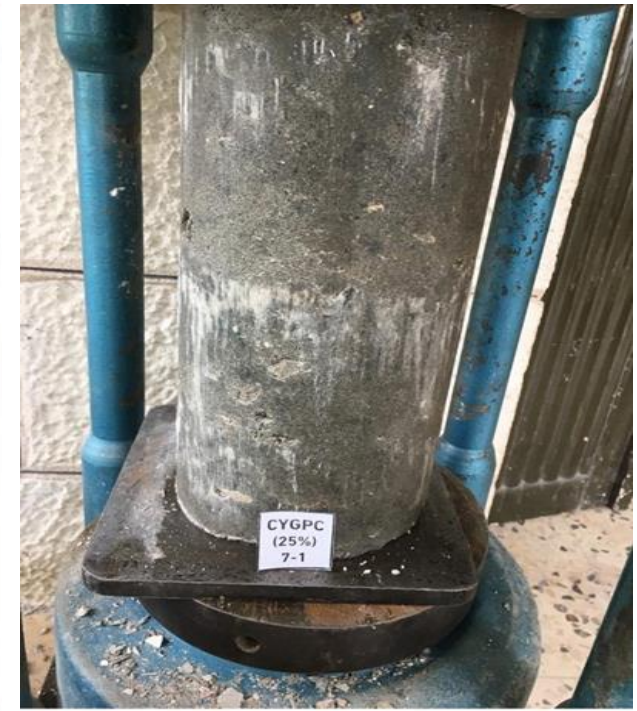

(c)

Figure.2: Resistance strength experiments for (A) Masonry cubes with 50\%Phosphorite wastes and 50\%Gypsum, (B) Phosphorite wastes fine and Gypsum concrete cubes, (C) Phosphorite wastes fine Gypsum concrete cylinders.

The figure 2 masonry and concrete test samples were prepared Including 36 masonry, 30 cubes and 20 cylinders. First, all masonry samples were classified to six main categories, depending on the ratio to cement (P, G, C), six cube samples with null Phosphorite wastes and Gypsum (MP), Six cube with 5\%Phosphorite wastes and 5\%Gypsum (MGPC5\%), Six cube

(MGPC10\%), Six cube (MGPC15\%), Six cube (MGPC25\%), and Six cube (MGPC50\%).

Table.1 shows the detailed mix design of cube masonry specimens, Phosphorite wastes, Gypsum that were used to prepare the cube masonry specimens: 
Table 1: Mix design of the tested cube masonry specimens

\begin{tabular}{|l|c|c|c|c|c|}
\hline \multicolumn{1}{|c|}{ Test samples (\%) } & Cement(kg) & Gypsum(kg) & Phosphorite(kg) & Fine(kg) & Water(ml) \\
\hline MP 7-28 day & 0.500 & 0 & 0 & 1.375 & $\mathbf{2 4 3}$ \\
\hline MGPC (5\%) 7-28 day & 0.475 & 0.00125 & 0.02375 & 1.375 & $\mathbf{2 4 3}$ \\
\hline MGPC (10\%) 7-28 day & 0.450 & 0.005 & 0.045 & 1.375 & $\mathbf{2 4 3}$ \\
\hline MGPC (15\%) 7-28 day & 0.425 & 0.01125 & 0.06375 & 1.375 & $\mathbf{2 4 3}$ \\
\hline MGPC (25\%) 7-28 day & 0.375 & 0.03125 & 0.09375 & 1.375 & $\mathbf{2 4 3}$ \\
\hline MGPC (50\%) 7-28 day & 0.250 & 0.125 & 0.125 & 1.375 & $\mathbf{2 4 3}$ \\
\hline
\end{tabular}

Secondly, concrete samples were grouped into the five main Four-cylinder specimens with $10 \%$ Phosphorite wastes and categories of cube and five cylindrical, totally based on the ratio cement(P, G, C), Six cube specimens with null Phosphorite wastes and Gypsum (CP) and Six cube specimens with $10 \%$ Phosphorite wastes and $10 \%$ Gypsum (CGPC10\%),Six cube (CGPC25\%), Six cube (CGPC35\%) and Six cubes (CGPC50\%). While Four-cylinder specimens with no Phosphorite wastes added and Gypsum (CyP) and 10\%Gypsum (CyGPC10\%), Four-cylinder (CyGPC25\%), (CyGPC35\%) and (CyGPC50\%)

The following Table (2) shows the detailed mix design proportion details of cube and cylindrical specimens Phosphorite , Gypsum:

Table 2: Proportion details of cube and cylindrical specimens

\begin{tabular}{|c|c|c|c|c|c|c|}
\hline Test Samples(\%) & Cement(kg) & Water(kg) & Coarse aggregate(kg) & Fine aggregate(kg) & Gypsum(kg) & Phosphorite(kg) \\
\hline СР , СуP & 14.68 & 7.3 & 41.8 & 32.256 & 0 & $\mathbf{0}$ \\
\hline $\begin{array}{l}\text { CGPC10\% } \\
\text {,CyGPC10\% }\end{array}$ & 13.12 & 7.21 & 41.8 & 32.256 & 0.156 & 1.404 \\
\hline $\begin{array}{l}\text { CGPC25\%, } \\
\text { CyGPC25\% }\end{array}$ & 10.78 & 7.069 & 41.8 & 32.256 & 0.975 & 2.925 \\
\hline $\begin{array}{l}\text { CGPC35\%, } \\
\text { CyGPC35\% }\end{array}$ & 9.219 & 6.9 & 41.8 & 32.256 & 1.91135 & 3.5 \\
\hline $\begin{array}{l}\text { CGPC } 50 \% \text {, } \\
\text { CyGPC } 0 \%\end{array}$ & 6.88 & 6.84 & 41.8 & 32.256 & 3.9 & 3.9 \\
\hline
\end{tabular}

\section{RESULTS AND DIALOG}

\subsection{Average Resistance strength for masonry}

Table 3: The mean Resistance strength of cement masonry

\begin{tabular}{|c|c|c|}
\hline Test samples & Mean MPA after 7 days & Mean MPA after 28 days \\
\hline MP & 16.744 & 18.92 \\
\hline MGPC (5\%) & 22.827 & 32 \\
\hline MGPC (10\%) & 25.56 & 33.76 \\
\hline MGPC (15\%) & 26.78 & 34.89 \\
\hline MGPC (25\%) & 28.88 & 36.95 \\
\hline MGPC (50\%) & 4.12 & 3.56 \\
\hline
\end{tabular}


The Engineering behavior and the Properties of Phosphorit and Gypsum on the Resistance strength of Concrete

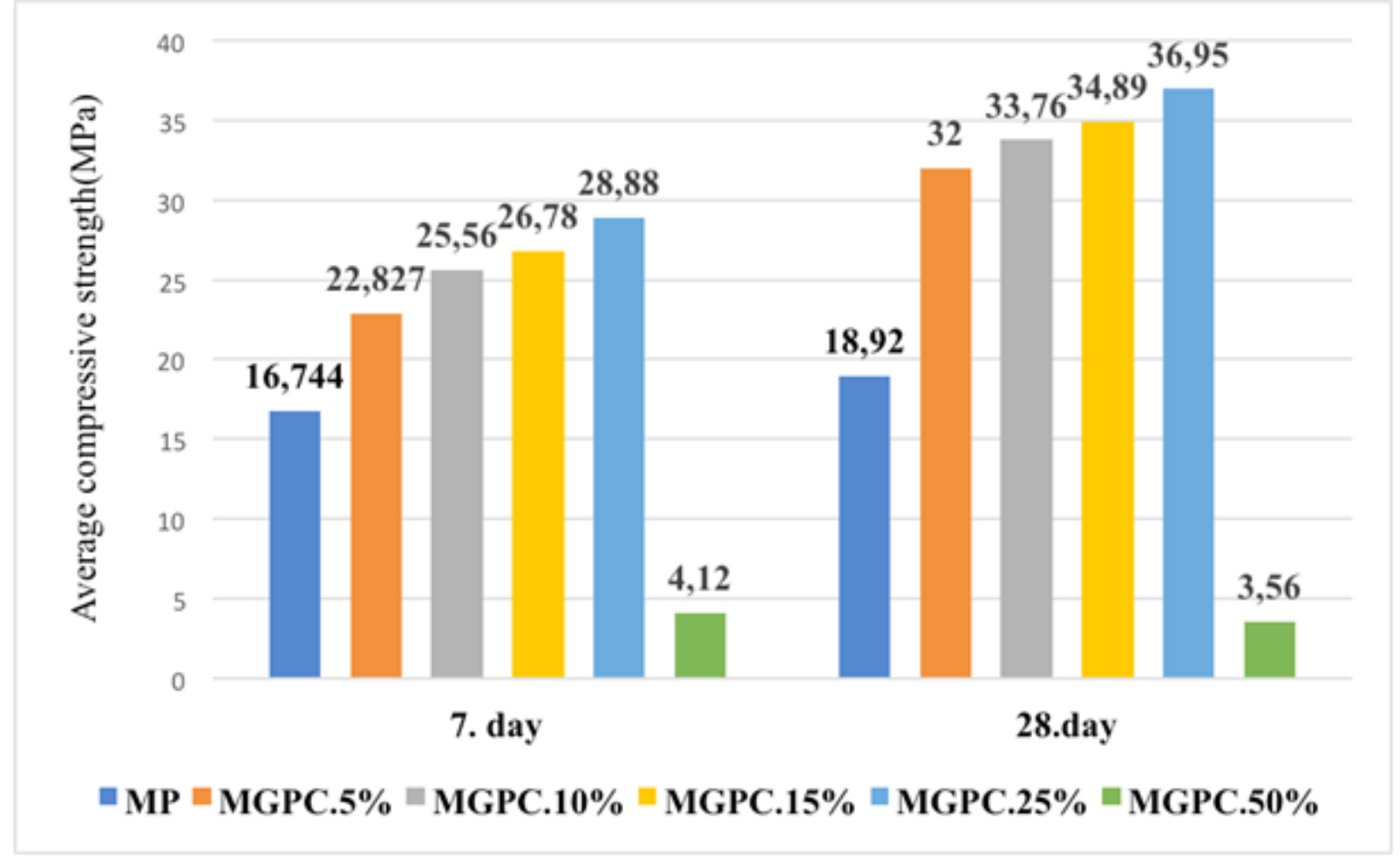

Figure 3: Mean resistance strength test conducted on the masonry group

Table 3 and Figure 3 results showed that of Resistance strength of cement masonry specimens at an age of 7 and 28 days. MGPC(5\%) increased the Resistance strength of cement masonry by a ratio of $26.65 \%$ and $40.9 \%$ an age of 7 and 28 days, respectively, MGPC (10\%) age of 7 and 28 days increased by a ratio of $34.5 \%$ and $44 \%$ respectively and MGPC (15\%) increased the by $37.5 \%$ and 45.77 , MGPC (25\%) increased the Resistance strength of cement masonry by $42 \%$ and $54.7 \%$, MGPC (50\%) at an age of 7 and 28 days decreased by a ratio of $30.64 \%$ and $43.15 \%$.

5.2 Resistance strength for cube

Table 4: The mean Resistance strength of concrete cubes

\begin{tabular}{|c|c|c|}
\hline Test Samples & Mean MPA after 7 days & Mean MPA after 28 days \\
\hline $\mathrm{CP}$ & 20.078 & 27.55 \\
\hline CGPC10\% & 23.11 & 29.11 \\
\hline CGPC25\% & 25.56 & 31.64 \\
\hline CGPC35\% & 7.52 & 8.937 \\
\hline CGPC50\% & 5.12 & 8.29 \\
\hline
\end{tabular}




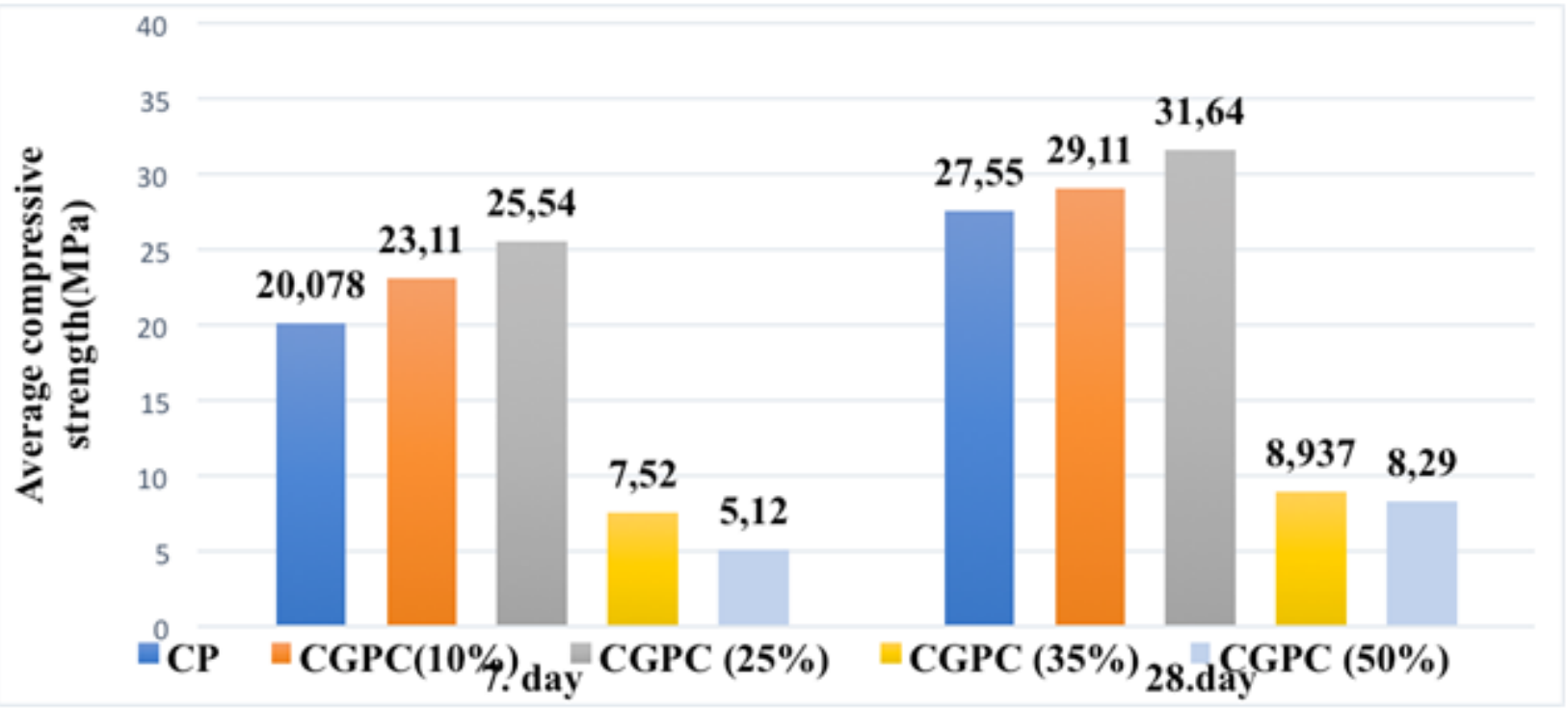

Figure.4: Mean Resistance strength test conducted on the concrete cubes

Table 4 and Figure 4 results showed that of CGPC10\% increased the Resistance strength of concrete cubes by a ratio of $13.12 \%$ and $5.36 \%$ at an age of 7 and 28 days, respectively. CGPC25\% increased by a ratio of $21.39 \%$ and $13 \%$, and concrete cubes CGPC35\% decreased the Resistance strength Table 5: The mean Resistance strength of concrete cylinders of concrete cubes by a ratio of $167 \%$ and $208 \%$. Finally, CGPC50\% decreased by a ratio of $292.15 \%$ and $232.3 \%$. 5.3 Average Resistance strength for cylinder

\begin{tabular}{|c|c|c|}
\hline Test Samples & Mean MPA after 7 days & Mean MPA after 28 days \\
\hline CyP & 17.545 & 18.25 \\
\hline CyGPC10\% & 19.67 & 22 \\
\hline CyGPC25\% & 29.8 & 22.84 \\
\hline СуGPC35\% & 5.94 & 8.6 \\
\hline CyGPC50\% & 5.38 & 8.22 \\
\hline
\end{tabular}

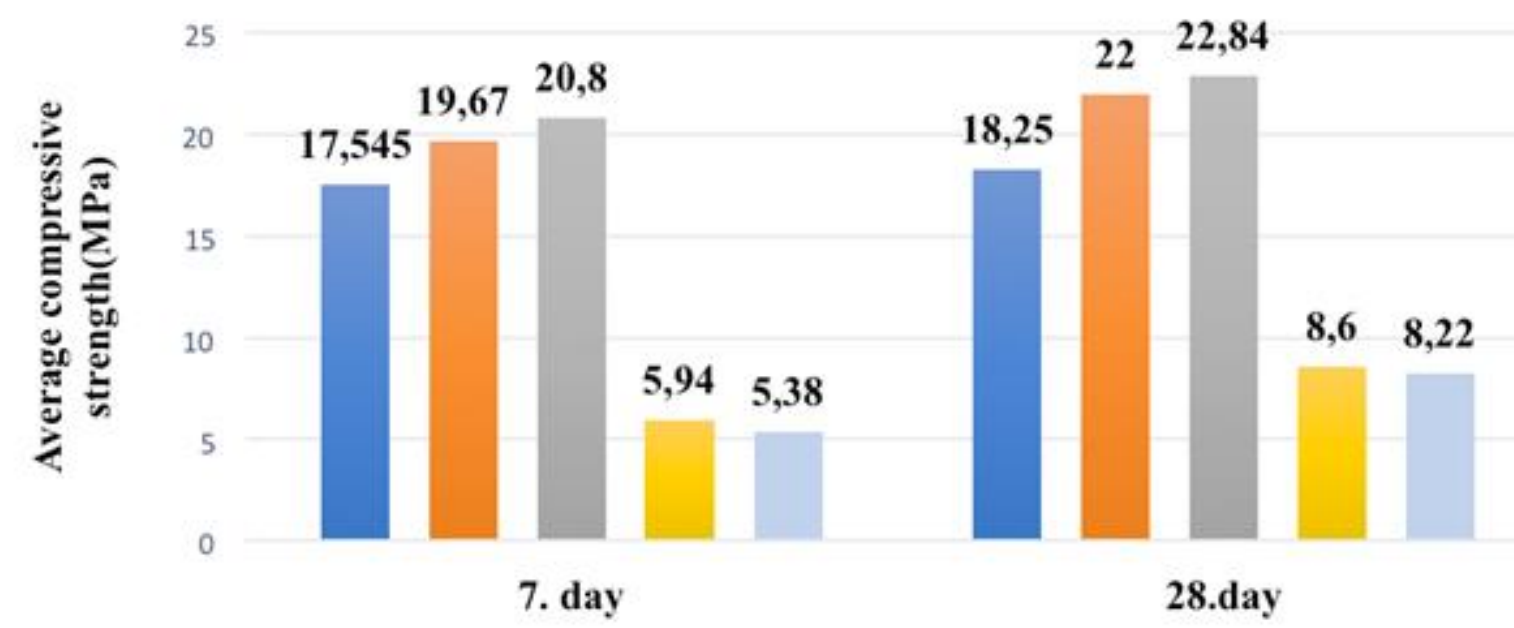

\section{$\approx \mathrm{CyP}=\mathrm{CyGPC}(\mathbf{1 0} \%)=\mathrm{CyGPC}(25 \%)=\mathrm{CyGPC}(35 \%)=\mathrm{CyGPC}(50 \%)$}

Figure 5: Mean Resistance strength at was conducted on the concrete cylinders 
Table 5 and Figure results showed that the concrete cylinders CyGPC10\% increased the Resistance strength of concrete cylinders by a ratio of $10.8 \%$ and $17 \%$ at an age of 7 and 28 days, respectively, CyGPC25\% increased by a ratio of $15.65 \%$ and 20\% respectively and CyGPC35\% decreased by a ratio of $195.4 \%$ and $112.2 \%$, CyGPC50\% at an age of 7 and 28 days decreased by a ratio of $226.11 \%$ and $122 \%$.

\section{CONCLUSION}

Current research on the effect of Phosphorite waste and Gypsum replacement of cement on concrete properties. A series of experiments were conducted on concrete. Cubes were poured and drunk in fresh water according to the ASTM Code. Cubes were tested at different ages 7 and 28 days. Based on the following conclusion the conclusion can be drawn; the replacement of cement by gypsum and Phosphorite increased the Resistance strength for concrete mixtures to certain limit, then the Resistance strength decreased and the best replacement ratio was $25 \%$ of cement which increased Resistance strength (for masonry $42 \%$, for concrete cubes $13 \%$, for cylinder $20 \%$ ). Also the Resistance strength has increased by the addition of Phosphorite due to presence of chemicals that increase the strength of their cohesion such as TCP P2O5, $\mathrm{CaO}$ and $\mathrm{SiO} 2$ and the Resistance strength has increased with gypsum due it cohesion proprieties and causes the permanent hardness in water.

\section{ACKNOWLEDGEMENT}

The authors are thank ful to the Jerash University by using their Laboratories and premises; Special thanks to Engineers for is helping in the laboratory. our thanks to reviewers for their valuable suggestions to enhance the quality of our article

\section{REFERENCES}

1. Sobolev, K., Flores, I., Torres-Martinez, L. M., Valdez, P. L., Zarazua, E., \& Cuellar, E. L. (2009). Engineering of SiO 2 nanoparticles for optimal performance in nano cement-based materials. In Nanotechnology in construction 3 (pp. 139-148). Springer, Berlin, Heidelberg.

2. Xu, H. H., \& Quinn, J. B. (2002). Calcium phosphate cement containing resorbable fibers for short-term reinforcement and macroporosity. Biomaterials, 23(1), 193-202.

3. Dubey, A. (2011). U.S. Patent No. 8,070,878. Washington, DC: U.S. Patent and Trademark Office.

4. Al Sharie, H. (2016). Properties of lightweight concrete containing treated pumice by alkaline solution. Jordan Journal of Civil Engineering, 159(3149), 1-8.

5. Yu, Q., Liu, Q., Grussing, J. F., Moyer, K. W., \& Spencer, R. (2004). U.S. Patent No. 6,822,033. Washington, DC: U.S. Patent and Trademark Office.

6. Alsharie, H., \& Alayed, O. (2019). The Effect of Replacing Fine Silica with Stone Cuttings' Powder on the Compressive Strength of Concrete: A Case Study in Jordan. Jordan Journal of Civil Engineering, 13(1)

7. Yu, Q., Sucech, S. W., Groza, B. E., Mlinac, R. J., Jones, F. T., \& Henkels, P. J. (2002). U.S. Patent No. 6,342,284. Washington, DC: U.S. Patent and Trademark Office.

8. Ghannam, S., Najm, H., \& Vasconez, R. (2016). Experimental study of concrete made with granite and iron powders as partial replacement of sand. Sustainable Materials and Technologies, 9, 1-9.

9. Sobolev, K., Flores, I., Torres-Martinez, L. M., Valdez, P. L., Zarazua, E., \& Cuellar, E. L. (2009). Engineering of SiO 2 nanoparticles for optimal performance in nano cement-based materials. In Nanotechnology in construction 3 (pp. 139-148). Springer, Berlin, Heidelberg.
10. Ghannam, S., Al-Rawi, O., \& El-Khatieb, M. (2011). Experimenta study on light weight concrete-filled steel tubes. Jordan Journal of Civil Engineering, 159(696), 1-9.

11. Yu, Q., Sucech, S. W., Groza, B. E., Mlinac, R. J., Jones, F. T., \& Boehnert, F. M. (2003). U.S. Patent No. 6,632,550. Washington, DC: U.S. Patent and Trademark Office.

12. Suliman, M. O., Alsharie, H., Yahia, Y. I., \& Masoud, T. (2017). Effects of Stone Cutting Powder (Al-Khamkha) on the Properties of Self-Compacting Concrete. World Journal of Engineering and Technology, 5(04), 613.

13. Ghannam, S., Al-Rawi, O., \& El-Khatieb, M. (2011). Experimental study on light weight concrete-filled steel tubes. Jordan Journal of Civil Engineering, 159(696), 1-9. 